\title{
FOREIGNERS' INTEGRATION AND LANGUAGE LEARNING IN ADULT EDUCATION IN CANADA: EXPERIENCE FOR UKRAINE
}

\author{
Mariia Busko (Corresponding author) \\ Liudmyla Huk, Halyna Kuzan, Nadiia Vilkhovchenko \\ Lviv Polytechnic National University, Lviv, Ukraine \\ mariyabusko@gmail.com
}

\begin{abstract}
The article deals with the research of special features of foreigners' integration and language learning in Canada as an integral part of adult education. The paper outlines a complex of basic scientific approaches such as system, structural and functional, andragogical, axiological, intercultural, and competency-based approaches. The study analyses a number of programmes for immigrants' integration in Canada, as well as language learning by adults. Critical overview allowed assuming that "Language Instructions for Newcomers to Canada" is the most popular programme among immigrants in this country. Taking into account the lack of similar programmes for foreign students in Ukraine and positive experience of Canada in this sphere, Lviv Polytechnic National University developed an elective course for international $\mathrm{PhD}$ students aimed at their adaptation in Ukraine. The article focuses on the features of the course which is based on the "Language Instruction for Newcomers to Canada" programme. Its content component is based on the demands, individual needs and involves the acquisition of language skills and acquaintance with the culture of the country. At the end of the course, the PhD students took part in a survey. The results of the survey showed that in spite of some difficulties, it appeared to be quite effective and informative.
\end{abstract}

Keywords: adult education; Canada; immigrant; immigrants' learning, integration; programme; language learning; newcomer.

\section{Introduction}

Globalisation processes at the beginning of the 21 st century are characterised by not only expanding the opportunities but also challenges in the social, economic, and political transformations of civilizations that determine the development of knowledge-based economy and new requirements for the labour market. On the way to European integration, Ukraine faces numerous problems, one of which is migration. The experience of Canada, a country with effective policy and national strategy aimed at solving problems of social, cultural, economic development of the society and its enrichment based on applying immigrants' potential, is valuable for Ukraine.

Adult education and immigrants' learning are issues that are investigated by scientists worldwide. Due to global transformational trends in education, in particular, such processes as constant technological and scientific progress and migration of a considerable number of adults in the world, the issue of adult immigrants' learning still does not lose its urgency and timeliness.

The issue of adult immigrants' learning, especially language learning, is very important both for the language and cultural policy of a country as well as for individuals who change their place of living arriving in other countries. One of the countries, where adult immigrant education is paid special attention and whose experience is worth studying and implementing is Canada. As revealed by the research, one of the main tasks of adult education in Canada is to assist immigrants in their adaptation to a new labour market and integration into Canadian society.

The research aims at the analysis of adult immigrants' language learning programmes in Canada and the evaluation of outcomes of using Canadian experience in Ukraine.

\section{Theoretical background}

The importance of adult learning is difficult to overstate so it is of considerable interest for researchers and scientists, who investigate into the new challenges arising before this area of education at present. Educators and researchers realise that "the difficult times in which we live require innovative, creative, and hopeful pedagogies of adult education" (Walter, 2019, p. 1). In this respect Boydell (2015) emphasizes on the need of new approaches in today's globalised world with its multiple problems involving people "with diverse and often conflicting values, aims, and aspirations, who need to cooperate with each other" and thus "require, among other things, the ability to empathise, appreciate, and respect others' culture, history, traditions, expertise, perspectives, and priorities, moving from monologue ... into dialogue" (p. 13). Bliss (2019) brings up an urgent problem of information society by asking the question if adults are equipped with skills to discern credible science-based resources. These skills are of primary importance because "in today's learning environment, adult learners conduct learning episodes on the Internet meaning they are now expected to approach a self-directed science-based learning endeavour with knowledge of digital tools 
(digital literacy), knowledge of the science content (science literacy), and critical thinking skills to evaluate online resources (information literacy)". Johnson (2015) focuses on adult language learning and emphasises the value of adult learning theory as its basis. He argues that it contributes to more profound and critical learning, broadens the aim of learning beyond the development of linguistic competence due to its transformative nature and learner-centeredness, focus on students' identities, experiences, needs and motivations.

Canada is one of the countries, where adult learning, specifically in terms of immigrant adaptation policy, plays a special role. As hundreds of thousands of immigrants of various ethnic origins and nationalities annually arrive in Canada they need educational, adaptive and integration services, which are usually provided to them before they arrive in the country. Special attention to adult immigrants' language learning as socio-cultural adaptation is paid through numerous programmes and initiatives. Significant attention of UNESCO (Adult education, 1997) to adult learning in the modern world is the confirmation of its role and significance. This organisation periodically holds conferences where decisions concerning the development of adult education are made. Later they become the basis of laws and normative and legal acts that outline the perspectives of adult education in different countries of the world.

Under the term "adult education" we understand the process of the knowledge and qualification acquisition by adults through practice, learning and experience in formal and informal education that can take place at home, at higher educational institutions, and at work. Adult education gives people an opportunity to enrich knowledge, improve professional and personal skills and qualifications, and is considered an important factor for the economic and socio-cultural development of the community in the 21 st century.

The research allows us to define the purpose and tasks of adult immigrants teaching. Modern adult education is aimed not only at providing opportunities to acquire relevant knowledge but also at motivating adults to broaden and apply it. The principles of adult education of immigrants were identified by McNair (2008) as an integral part of lifelong learning and included: timely learning, collaboration skills development, promoting sustainable community development, learning for the sake of the future (McNair, 2008). Researching adult immigrants' learning in Canada, Grabke (2009) came to the conclusion that according to competency approach the level of educational background has a significant influence on further learning of immigrants and their work perspectives.

Having analysed the system of Canadian adult education, four key perspectives have been singled out: global (promoting international competitiveness); economic (solving the problem of employment, vocational training); social (support of active social and civic stance); and personal (continuation of personal development) (DebBurman, 2005). Among its priorities we would like to outline the promotion of democracy and cultivation of active citizenship; development of literacy and basic adult education; creating the relevant conditions for studying at the workplace; use of information and communication technologies, mass media for educational purposes; meeting educational needs of the country's population.

Considering the purposes of Canadian adult education system, we defined the following main functions: adaptive (as adults adapt to the requirements of society and changes occurring in it); compensatory (as it provides adults with the opportunity to overcome the lack of appropriate and necessary knowledge and skills because of improper previous education); developing (as adults acquire cultural and spiritual enrichment); analytical (as education includes the analysis of adults' needs in order to respond to them as effectively as possible); communicative (transferring of experience, knowledge, and values from one generation to another); motivating (people are motivated to continue learning or mastering new knowledge in adulthood); prognostic (predicting the needs of society according to the features of its development).

\section{Methods}

To carry out the research the following methods have been applied: comparative content analysis with the aim of determination of main characteristics of adult language programmes in Canada and experimental implementation of such kind of programme in Ukraine with the analysis of the results; questionnaire and interview with participants of the experimental programme in Ukraine.

Our idea was to adopt and implement one of Canadian programmes in Ukraine. In order to verify the efficiency and benefits of the language programme "Language Instructions for Newcomers", we implemented the programme on the basis of Lviv Polytechnic National University for $\mathrm{PhD}$ foreign students $(\mathrm{n}=15)$ of the first year of study. This programme was adopted and developed on the basis of the programme "Language Instructions for Newcomers to Canada" as it turned out to be the most successful in Canada. The programme lasted for one semester and included different topics for newcomers to become familiarised both with social and cultural life in Ukraine and Lviv and the basics of Ukrainian language in particular. Bearing in mind the 
socio-cultural component of the programme, we added some extracurricular activities that were not introduced in the Canadian programme: sightseeing tours, interviews with Ukrainian $\mathrm{PhD}$ students, meetings with foreign $\mathrm{PhD}$ students who had been studying at Lviv Polytechnic University for more than 2 years.

The fundamentals of Ukrainian language were taught through different methods and techniques. The first 5 lessons were accompanied with explanation in English and translation as the students had different language, social and cultural background (the Chinese, the Koreans, the Arabs, Europeans, the Africans etc.). The following lessons were mostly monolingual (in Ukrainian) without English language medium. The initial Ukrainian language level of all students was below A1 (CEFR), as they had to pass an entrance exam in English and did not need the working knowledge of Ukrainian which was an elective course in their study. So we did not perform the initial language level assessment. But for the successful adaptation into the university community students needed basic survival knowledge of Ukrainian language (A1-A2). That is why they were recommended to complete the course of Ukrainian. The final test and interview were held after the programme implementation that included formal lessons and additional extracurricular activities. The programme envisaged both oral and written language learning. Special emphasis was laid on practical topics related to personal information, telephone conversation, interviewing, shopping, medical servicing, etc. As the students were on the starter level of Ukrainian, the most of learning materials were audio-visual with some support of tradition course books for foreigners.

The final questionnaire was aimed at verifying the outcomes of the programme and students' attitude to it. We suggested five questions for consideration: 1) What was the most difficult at the initial stage of your stay in Ukraine in terms of communication and studying? 2) Is there a need for the programme of Ukrainian language and culture? 3) Was the programme beneficial for you? Mention some benefits. 4) How will you assess the following components of the programme according to 5 points scale ( 1 for very bad and 5 for great): organisation, content, extracurricular activities? 5) What would you change or add to the programme?

\section{Results}

Having conducted the comparative content analysis of Canadian adult language learning programmes, we have found out that the content of adult immigrants training is aimed at providing them with the necessary knowledge and skills, as well as values that they will need for adaptation in a new society. Adult immigrants in Canada are engaged in acquiring a wide range of knowledge. Firstly, they learn various areas of humanities (knowledge of the spiritual, mental, cultural, social spheres of human activity, language, norms of morality, welfare, standards of conduct in the Canadian society, rights and duties of citizens). Secondly, adults also have opportunity to gain socio-economic knowledge (political, economic, legislative systems of Canada, education system, daily life, transport and banking systems, communication tools, health and safety, services, insurance, etc.). Finally, they acquire specialised and practical knowledge, including skills of business and professional language. Thus, adult immigrants' learning involves the formation of asserts inherent to the Canadian society, namely, moral, ethical, spiritual, social, civic, and democratic values.

The analysis of the features of the immigration process in Canada shows that assistance to immigrants in the organisation of their education is implemented in two stages, before the arrival to the country and after that. So, before arriving in Canada potential immigrants get acquainted with the specific features of life in the country, its customs, traditions, and way of life, as well as moral, ethical and social values promoted by the Canadians. Upon arrival, the process of training of adult immigrants usually begins with the study of one of the official languages through the following initiatives: "Language Instructions for Newcomers to Canada" (basic language learning); English as a Second Language (ESL) and French as a Second Language (FSL), Enhanced Language Training that provide Professional Language Courses.

The majority of people are enrolled for "Language Instructions for Newcomers to Canada". The reason is that they do not have to pay for participation; they are suggested different levels of learning and are not time-limited. English as a Second Language is also in demand as it offers different skill levels and is designed for specific purposes. "Enhanced Language Training" is usually an intensive programme which helps to raise language proficiency and assists in finding a job. It lasts only a few weeks and is usually in full-time form. One of the least popular language programmes is French as a Second Language as this language is spoken only in Quebec and partly in some other provinces.

Table 1 shows the range of language programmes and forms of learning within them. Applying structural approach for studying adult immigrants' learning programmes in Canada, we identified a system of components, which are interdependent and complementary and fulfils certain functions (adaptive, compensatory, developing, analytical, communicative, motivating, prognostic, integrating). The programmes are based on appropriate educational principles: recognition of the right for education, orientation on human values, consistency, urgency, suitability and sustainability. It is realised through a certain context (system of 
adult education in Canada) and relies on a normative and legal basis (laws, strategies, plans of actions, budgets, initiatives, programmes). According to the systematic approach to adult immigrants' learning, we may conclude that the programmes are an educational system that includes such systemic components as purpose, content, operation, control and regulation, results estimation and reflection.

Table 1

\section{Language Programmes in Canada}

\begin{tabular}{|l|l|l|l|l|}
\hline Language Programme & $\%$ & $\begin{array}{l}\text { Participation by Immigration } \\
\text { Category (Mostly) }\end{array}$ & Form of learning & $\%$ \\
\hline $\begin{array}{l}\text { Language Instructions } \\
\text { for Newcomers }\end{array}$ & 42 & $\begin{array}{l}\text { Family class } \\
\text { Refugees }\end{array}$ & Full-time & 25 \\
\cline { 3 - 5 } & 26 & $\begin{array}{l}\text { Skilled Workers } \\
\text { Business Class } \\
\text { Language (ESL) }\end{array}$ & Distance & 29 \\
\hline $\begin{array}{l}\text { French as a Second } \\
\text { Language(FSL) }\end{array}$ & 9 & $\begin{array}{l}\text { Skilled Workers } \\
\text { Business Class }\end{array}$ & Full-time & 27 \\
\cline { 3 - 5 } & 23 & $\begin{array}{l}\text { Skilled Workers } \\
\text { Business Class }\end{array}$ & Online course & 28 \\
\cline { 3 - 5 } $\begin{array}{l}\text { Enhanced Language } \\
\text { Training }\end{array}$ & Full-time & 21 \\
\cline { 3 - 5 } & & Part-time & 41 \\
\hline
\end{tabular}

It has been found out that a great advantage of this programme is practical training. The specialists in social, medical and legal spheres attend the language learning classes to introduce and discuss different reallife situations, give some advice on how to behave, and answer immigrants' questions.

One more distinguishing characteristics of "Language Instructions for Newcomers to Canada" is the possibility to go sightseeing, visit museums, galleries and other places of historical interest, which is both positive for learning and integration into a new society. At the end of each year, learners pass the test to identify their language level and find out if they are ready to take the higher level of the programme.

Our version of adaptation of the Canadian programme included 7 main topics for learning and lasted for only 1 semester (36 face to face academic hours and 18 extracurricular academic hours). The choice of topics was based on students' communicative needs, the grammar themes were selected according to the content, students abilities and communicative necessity. The form of the organisation was formal lessons and extracurricular activities (excursions, meetings, consultations). While implementing the programme, we faced a number of difficulties. First of all, they appeared because of time-restriction as students had only one semester to learn the basis of Ukrainian and after that, they continued their study at the chosen $\mathrm{PhD}$ course. Also Ukrainian language level of newcomers was quite low, which caused some difficulties in presenting the information. Therefore we chose to apply methods of the natural approach mainly: immersions, audio-visual, and direct one.

Analysing the results of our survey and anonymous questionnaire connected with the implementation of the adopted language programme in Ukraine, we have found out positive outcomes of the initiative. The answers to the first question showed that the Ukrainian language, as well as communication, was the most difficult issue for all students when they started to live in Ukraine (especially, different alphabetic system and grammar). 10 students noted that it was a culture that seemed to be quite strange for them. They faced certain difficulties in communicating with people in public establishments.

Answering the second question, all students underlined the necessity of the programme and 18 students wrote that they would like to study Ukrainian language for the academic purposes. As for the third question, $19 \mathrm{PhD}$ students admitted that this programme helped them to adapt in Ukrainian society, as they got acquainted with Lviv history, cultural features of Ukrainian people and acquired some basic language skills.

Answers to the fourth question, concerning the assessment of the programme, showed that 11 students were quite satisfied with all its components, 8 students preferred an online format to the full-time programme. Finally, all students wanted to increase the length of the programme, as one semester was not enough for them to master the Ukrainian language and learn the features of the culture. They noted that such programme should last at least one year. 


\section{Discussion}

It is well-known that Canada is a multinational country that supports the cultural diversity of its society. Our research highlights the importance of moral, ethical, spiritual, social, and civic values formation during the language learning. Our idea is confirmed by Mukan and Shyika (2017) who stated that "at the beginning of the 21st century, special attention is paid to education whose main task is to prepare a person for functioning in a multicultural society" (p. 35).

The research findings suggest that according to immigrants' needs all language learning programmes in Canada are divided into those for basic and specific purposes. The programme "Language Instructions for Newcomers to Canada" is the most widespread among adult immigrants, especially those, who have little or no knowledge of English or French. The strength of this programme is that it promotes not only language learning, but also the social values of Canada. These findings are in line with the study of Dempsey (2009), a programme researcher, who claimed that by developing communication skills through this programme, immigrants can better function in Canadian society and contribute to the country's economic development. We absolutely agree with the results obtained by Lee (2002), who makes a conclusion that preparation for life in a new society on formal and informal levels influences learning in considerable ways, especially learning a language. He emphasised that essential factors that should be taken into consideration are immigrants' culture, diversity between immigrants' and indigenous population culture as well as whether the immigration was voluntary or forced.

Considering the analysis of the results of the programme implementation, its benefits are obvious and supported by students answers in the questionnaire and during the personal interview with participants, language teachers, scientific supervisors after the programme completion. However, we have to mention some challenges and disputable points of the programme implementation in Ukraine.

First, the main challenge was the low language level of students. Operating component of the programme for international $\mathrm{PhD}$ students in Ukraine was represented by a large variety of forms and teaching methods that enabled them to acquire the necessary language knowledge, to form and develop new skills. The most efficient among them were natural approach methods: language immersion, total physical respond, direct and oral methods (Thornbury, 2017). Consequently, we applied the methods of the natural approach to language learning. These methods are not modern or new, but their advantage is the possibility to acquire target language without a native language medium in case when a student and a teacher speak different languages. That is why we developed the following scheme: the first three lessons were conducted in Ukrainian with frequent switching to English, then in the next two lessons we gradually decreased the amount of English, and the rest of lessons were delivered only in Ukrainian. This scheme seemed appropriate for students to eliminate the stress from immediate switching into a completely unknown language. The choice of the topics was determined by the students' communicative needs. The meaningful content of the programme was of higher priority for us than the language form. We decided to teach grammar at the point of need in order not to overload students with unnecessary information and terms.

In our opinion, the key educational factor that allowed us to carry out the programme is the application of natural approach methods toward language acquisition. The natural approach to the language learning defined by Krashen and Terrell (1996) implies language immersion and integrates naturalistic principles of native language acquisition into successful second language learning. It is less focused on teacher's speech production and formal grammar issues, and, consequently, the accurate production of target language structures is not demanded. The natural approach priority is an exposure rather than practice; it highlights the emotional alertness for learning; implies a lengthened period of audio-lingual messages before students try to respond (pre-production phase). The main methodological strategies are total physical respond (commandbased), strategies of the direct method (gesture and context), immersion and oral (situation - based activities aimed at eliciting and training of patterns and structures) methods. The main benefits of the approach are the minimisation of anxiety and the maximisation of self-confidence. As recommended by scholars (Bell, 2007; Thornbury 2017; Richards \& Rodgers, 2014), we tried to avoid grammar rules drillings. Instead, we put the main emphasis on vocabulary, created a stress-free environment, did not force students to communicate, chose understandable, interesting, and motivating topics for the communication.

However, we should mention some drawbacks of the approach. The described methods are useful for speaking and listening skills development, but literacy, reading and writing are left behind. We regard the question of error correction rejection during the initial stage, due to lack of grammar explanation, as a disputable one because some mistakes may transfer into the fossilisation that is quite hard to change. Thus, we suggested that teachers should decide for themselves what and how to correct. In order to balance the language learning outcomes, we propose to apply more conventional methods of language learning following the initial period when natural methods were used. The duration of the initial period can be defined by a teacher. 
The second challenge was connected with the including of the socio-cultural component into the language learning programme, as it is suggested in the original Canadian programme, because successful integration into the society requires the knowledge of culture and traditions of the host country. This component was introduced through informal mentoring, pairing, and extracurricular activities. Mentoring implies engagement of the scientific supervisor as a mentor of language training. Supervisors gave consultations both in English and Ukrainian and monitored the language improvement together with language teachers. Due to these activities, we increased time for training and connected language with fieldrelated topics. For pairing activity, we engaged Ukrainian $\mathrm{PhD}$ students to make pairs with foreign learners and assisted them with language as well as socialising. We took into consideration the language needs of students in professional activity and everyday life as well. Thus, we engaged in communication not only teachers, students and scientists, but also specialists from the medical and legal spheres who attended classes to introduce some issues and give some advice. We tried to engage the native language community (students, supervisors, guides, invited field related specialists) to the process to enforce the socio-cultural component of the language acquisition.

Considering everything mentioned above, we have outlined the following key elements of a language training model:

- language skills and knowledge should be acquired through career-long learning;

- access to natural approach learning methods and tools followed by the application of conventional methods is crucial for successful language acquisition;

- native language community support should be an integral part of the language training;

- language training should be performed by quality-assured providers.

The suggested language learning programme for adults is an attempt to help international students integrate into Ukrainian society. It gives the opportunity not just to acquire language skills but also to understand Ukrainian way of life and features of culture. It is important for them to succeed as learners and researchers as well as members of Ukrainian society.

\section{Conclusions}

The study has revealed that the language training of adults is a process of knowledge acquisition, skills and values formation and development, which meets the requirements of the scientific, technological, social, cultural, and political progress. This process is ensured by the implementation of target programmes and different forms of learning. Adult language training consists of different components that constitute a system. By means of the suggested programme, the adults are provided with opportunities to acquire knowledge necessary for adaptation and being successful members of a new society; to master both everyday and professional language; to shape and develop communicative skills necessary for the adaptation; to get acquainted with the social, cultural, and economic spheres of life; to become familiar with the traditions and values of the country.

Having studied the experience of Canada in terms of adult language learning and adaptation, Lviv Polytechnic National University designed an elective course for international $\mathrm{PhD}$ students aimed at their adaptation in society. Their individual needs determined the content component of the training course. It covered language learning, development of communicative skills with consideration of their cultural background. The content component also included the acquaintance with the Ukrainian culture and traditions. The findings of the study have proved that despite the difficulties which arose during the programme implementation, it can be quite effective and informative for newcomers to Ukraine.

\section{References:}

Adult education. The Hamburg declaration. The agenda for the future. (1997). Hamburg, UNESCO Institute for education. Bell, D. (2007) Do teachers think that methods are dead? ELT Journal, 61, 135-143. https://doi.org/10.1093/elt/ccm006

Bliss, A. C. (2019). Adult science-based learning: The intersection of digital, science, and information literacies. Adult Learning, $X X(\mathrm{X})$. https://doi.org/10.1177/1045159519829042

Boydell, T. (2015). Facilitation of Adult Development. Adult Learning, 27(1), 7-15. https://doi.org/10.1177/1045159515615111

DebBurman, N. (2005). Immigrant Education: Variations by Generation, Age-atImmigration, and country of origin. New York, the USA: LFB Scholarly Publishing LLC.

Dempsey, C. (2009). Language Instruction for Newcomers to Canada: Client profile and performance indicators. Citizenship and Immigration Canada. Retrieved 12 January 2019 from https://www.canada.ca/content/dam/ircc/migration/ircc/english/pdf/r esearch-stats/linc-indicators.pdf

Financial Literacy: Resources for Newcomers to Canada (2008). Toronto, Canada: Social and Enterprise Development Innovations.

Grabke, S. (2009). Economic adjustment of adult immigrants and the role of postsecondary educational institution. Canada: Canadian Council on Learning.

Home Instruction for Parents of Preschool Youngsters (n.d.). Retrieved November, 2018 from www.hippycanada.ca

Johnson, S. M. (2015). Adult Learning in the Language Classroom. Bristol, UK: Multilingual Matters. 
Krashen, S. \& Terrell, T. (1996) The Natural Approach: Language Acquisition in the Classroom. Revised Edition, Janus Book Pub/Alemany Pr.

Lee, M. \& Sheared, V. (2002). Socialization and immigrant students' learning in adult education programs. New Directions for Adult and Continuing Education, 96, 27-36. https://doi.org/10.1002/ace.76

McNair, S. (2008). Migration, communities and lifelong learning. Leicester: National Institute of Adult Continuing Education.

Mukan, N., Shyika, Yu., \& Shyika, O. (2017). The development of bilingual education in Canada. Advanced Education, 4(8), 35-40.

https://doi.org/10.20535/2410-8286.100924

Ontario Ministry of Training, Colleges and Universities (2000). Literacy profile of Ontario's immigrants. Toronto: Government of Ontario.

Richards, J. C., \& Rodgers, T. S. (2014). Approaches and methods in language teaching (3rd ed.). Cambridge: Cambridge University Press.

Thornbury, S. (2017). 30 Language Teaching Methods. Cambridge: Cambridge University Press

Unlocking Canada's Potential: The State of Workplace and Adult Learning in Canada (2007). Ottawa: Canadian Council on Learning.

Walter, P. (2019). Innovations in teaching adult education: Living history museums and transformative learning in the university classroom. Adult Learning, XX(X). https://doi.org/10.1177/1045159519826074 